Article

\title{
The Role of Cynicism and Personal Traits in the Organizational Political Climate and Sustainable Creativity
}

\author{
Qi Zhang ${ }^{1}$, Siwei Sun ${ }^{2}$, Xingshan Zheng ${ }^{1, *(\mathbb{D})}$ and Wei Liu ${ }^{3, * \mathbb{D}}$ \\ 1 Antai College of Economics and Management, Shanghai Jiao Tong University, Shanghai 200030, China; \\ chyizhang@sjtu.edu.cn \\ 2 International Business School Suzhou, Xi'an Jiaotong-Liverpool University, Suzhou 215123, China; \\ Siwei.Sun17@student.xjtlu.edu.cn \\ 3 Discipline of International Business, The University of Sydney, Sydney 2006, Australia \\ * Correspondence: xszheng@sjtu.edu.cn (X.Z.); wei.liu2@sydney.edu.au (W.L.)
}

Received: 18 December 2018; Accepted: 2 January 2019; Published: 7 January 2019

\begin{abstract}
Innovation, as the key concern of sustainable human resource management, is one of the motivators of the sustainable development of organizations. However, past literature believes that innovation may be hindered by the organizational political climate. Based on the self-determination theory, this study proposes a new perspective to transfer the effect of this climate on innovation through the mediating role of cynicism and the moderating role of personal trait regulatory focus. Findings from 341 seven-point Likert survey questionnaires of employees in a Chinese automobile enterprise revealed that: first, the organizational political climate (expect interpersonal relationships) negatively predicted radical creativity and incremental creativity; second, organizational cynicism mediates the negative relationship between the organizational political climate and radical creativity and incremental creativity; third, the mediating effect of the organizational cynicism relationship between the organizational political climate and dualistic creativity could be affected by the personal trait regulatory focus. This study fills the gap in the relationship between organizational political climate and innovation. Additionally, this study proposes several suggestions for the practitioners and further research.
\end{abstract}

Keywords: sustainable human resource management; organizational political climate; organizational cynicism; personal trait regulatory focus; employee innovation

\section{Introduction}

The appeal of the sustainable development of society motivates enterprises to change their model and strategies into more long-term objects related to human issues [1,2]. Although past literature continuously explores the issues related to sustainability [3], the concept of sustainability still remains disputed in different research fields [4,5]. People, the environment and profitability are the three main focuses of the sustainability of enterprises [6]. As one research stream that focuses on how to influence individuals and groups in developing attitudes and behaviors consistent with a sustainable approach [7], human resource management that has been verified to contribute to the development of enterprises, initiating a new research direction in human resource management: sustainable human resource management, covering a comprehensive scope $[8,9]$. In the study of sustainability, the contents of sustainable human resource management are also widely discussed [10-13]. In this study, the main tasks of sustainable human resource management are narrowed into attracting and retaining talented employees with establishing a healthy and open work environment to motivate the organization to achieve long-term development [12]. On this occasion, how to find individuals 
with talents and inspire employees' potential talents is extremely important [14,15]. Talent is not only a term referring to people but also the characteristics of people, such as abilities, knowledge and competencies [15]. Innovation as an important capability is the scope of management and the motivator of the development of an organization [16]. However, the existence of an organizational political climate that initiates in enterprises the self-interest behaviors of employees, a scarcity of resources and the ambiguity of managerial policies have been considered to negatively influence the attitude and behaviors of employees, including innovative behavior [17]. Although most researchers believe that the organizational political climate may decrease the innovation of employees, the mechanism between their relationships still needs more discussion. For example, the negative effect of organizational cynicism derived from the organizational environment may turn weak, indirectly promoting the attitudes of employees [18].

Based on self-determination theory, this study attempts to explore the mechanism by which organizational political climate influences creativity, including radical creativity and incremental creativity. In this paper, research will answer the following questions: what is the role of the organizational cynicism in the organizational political climate and how it affects employees' creativity? Can the personal trait regulatory focus be regarded as the boundary condition of analyzing the relationship between organizational political climate and creativity? How do organizational cynicism and personal trait regulatory focus work on the way organizational political climate affects creativity? The rest of this paper is organized into five sections. Section 2 reviews previous studies to give a brief introduction of background and develops a conceptual model framework. Section 3 describes the research method. Section 4 shows the results of the model hypotheses and path coefficient analysis. Section 5 discusses the relationship between innovation, talent management and sustainable business development. Section 6 summarizes the main conclusions and insights of this paper and discusses shortages and further studies. Organizational innovation is the core force of the sustainable development of organizations.

\section{Background and Research Model}

\subsection{Organizational Political Climate and Employee Creativity}

Organizational political climate is the shared perceptions of practices associated with organizational recruitment, organizational decision-making, the achievement of goals, and the allocation of resources and rewards [19]. Although the effect of organizational political climate on individuals and organizations may not always be negative, the scarcity of resources and the ambiguity of managerial policies may cause negative competition among members of organizations and self-interested behavior that may lead to negative behavior [19,20]. A negative organizational political climate tends to destroy the contract between employees and the organization, indirectly destroying communication among individuals, performance and the proactive intentions of individuals, and the establishment of shared values in the organization $[19,21,22]$. To be specific, in a high-level organizational political climate context, the operation of an organization will be affected by many other factors (such as power and relationship), making people attach too much importance to self-interest, salary and welfare, and interpersonal relationships. After all these factors, the internal relationship between employees and the organization will be weakened, leading to passive behaviors. Therefore, as employees are in a high organizational political climate, their innovative behavior will be curbed.

In addition, the appearance of organizational politics is often accompanied by certain uncertainty and ambiguity in policies, leading to a low level of employee safety and engagement due to doubt in guarantees and supports from organizations [19]. As a kind of behavior, innovation behaviours of employees are influenced by organizational climate [23]. If the organizational political climate is maintained at a high level, the attitudes of employees will be passive, and the intentions of innovation will decrease.

Previous studies have shown that the boundary conditions should be considered by researchers studying the influential process of organizational political climate [24]. Therefore, this study explores 
the effect of organizational political climate from three dimensions (self-interest, salary and promotion and interpersonal relationship). In terms of creativity, it is also hard to measure through a single dimension $[25,26]$. Therefore, this research classifies creativity into radical creativity and incremental creativity, aiming to better understand the role of certain factors and related influences [27-29]. Radical creativity refers to innovative practice that is totally different from the existing condition, and incremental creativity refers to a minor change in the existing framework for improvement [27]. According to the above, this study hypothesizes that:

Hypothesis 1a. Self-interested behavior negatively predicts radical creativity and incremental creativity respectively.

Hypothesis $\mathbf{1 b}$. Salary and promotion negatively predict radical creativity and incremental creativity respectively.

Hypothesis 1c. Interpersonal relationship negatively predicts radical creativity and incremental creativity respectively.

\subsection{Organizational Cynicism}

At the end of the last century, scholars first proposed organizational cynicism based on a philosophical concept and extended the study of cynicism in a new direction [30]. Organizational cynicism referring to the negative and negative attitude of employees towards the organization generally exists in the organizational environment and occurs in the initial stage of the contract relationship [31]. Organizational cynicism has three aspects, including employees' beliefs, feelings and behaviors towards the organization [32]. The appearance of organizational cynicism can be attributed to problems within the organization, such as technical defects in the organizational system, leadership, environment, etc. [33].

The characteristics of organizational cynicism are as follows: the first is perniciousness. As a negative psychological state (e.g., disappointment, anger, frustration, etc.), cynicism can reduce the performance of employees in the organization and the willingness and efficiency of labor [30,34]. Second is diffusivity. The appearance of cynical individuals within the organization will further affect the specific performance of other employees in the organization [35]. Third is multi-dimension: organizational cynicism may reflect three aspects: belief, emotion and behavior [36]. Fourth is adherence: organizational cynicism exists in organizational contexts, directly affecting the employment relations [37]. Fifth is dynamics: organizational cynicism is derived from the organizational environment and can be accompanied by the dynamic change of organizational environment, time and organizational structure [30]. On the one hand, the antecedents of organizational cynicism are the perceptions of the workplace, such as political perception, fairness, psychological contract breath, and organizational support perception [38].

As this study argues that the organizational political climate will negatively influence the perceptions of employees, organizational cynicism, a negative attitude towards the workplace, will increase. On the other hand, consequences of organizational cynicism are considered as negative perception towards workplace, organizational citizenship behavior and performance [30,32]. Therefore, it can be inferred that the high level of organizational cynicism creative behavior may decrease. As organizational cynicism is maintained at a high degree, employees may lose confidence in the organization, accompanied by a series of adverse behaviors such as lying, burnout [39]. On the contrary, if few employees show negative attitudes to the organization and work, they may be more willing to work efficiently and spare no effort in making use of their talents and knowledge for innovation [38]. Furthermore, the effect of organizational cynicism may change with time and organizational situation $[40,41]$. According to the above, this study hypothesizes that:

Hypothesis 2a. Organizational cynicism mediates the relationship between self-interest behavior and creativity. 
Hypothesis 2b. Organizational cynicism mediates the relationship between salary and promotion and creativity.

Hypothesis 2c. Organizational cynicism mediates the relationship between the interpersonal relationship and creativity.

\subsection{Personal Trait Regulatory Focus}

Most studies explore the outcome of the organizational political climate and organizational cynicism from the perspective of their negative effects [42]. However, the cynicism is changing all the time because of its adherence to the organizational environment, time and organizational structure. Additionally, the negative effect of organizational political climate and organizational cynicism may be improved due to the improvement of what has been regarded as the key of competitiveness of enterprise " $\mathrm{H}$ ". Enterprise " $\mathrm{H}$ " provided a rich situation. According to self-determination theory, individuals may be proactive in order to change their life situation. Some scholars consider organizational cynicism as a personal trait and the negative psychological situation can be changed [18,30]. Employees have two different self-regulatory tendencies in the process of pursuing goals: facilitating personal trait regulatory focus and defensive personal trait regulatory focus [43].

Individuals with facilitating personal trait regulatory focus are more sensitive to the acquisition of positive results as they pursue self-realization, and therefore they have stronger motivations to achieve goals. By contrast, individuals with defensive focus are afraid of loss and they are more sensitive to negative outcomes, and therefore, they have stronger incentives to avoid loss. As a stable individual characteristic, the personal trait regulatory focus has been proved to be an important moderator the attitude and behavior of employees in many studies [44]. Employees with facilitating regulatory focus may easier to identify potential opportunities with decreasing the negative effects of lacking self-efficacy [45].

From the perspective of self-determination theory, people with different personal trait regulatory focus have various attitudes toward pressure due to the political climate, indirectly influencing their attitudes toward innovation. The employees with facilitating personal trait regulatory focus will devote their enthusiasm to conduct actions to overcome the problems [46]. The employees with facilitating personal trait regulatory focus are more self-confident and radically creative [47]. Besides, these people will be more willing to modify the improper situation based on their knowledge [48]. By contrast, people with defensive personal trait regulatory focus are more willing to avoid huge change to avoid uncertain results [49]. Therefore, they may be more willing to modify gradually to undermine negative effects. Thus, this study hypothesizes that:

Hypothesis 3a. Facilitating personal trait regulatory focus moderates the relationship between organizational cynicism and radical creativity.

Hypothesis $3 \mathbf{b}$. Defensive personal trait regulatory focus moderates the relationship between organizational cynicism and incremental creativity.

Personal trait regulatory focus can be adopted as a kind of intervention to guide the psychological situation of individuals [42]. Therefore, this study adopts personal trait regulatory focus as a moderator in the whole path by which political climate influences creativity. To be specific, the negative effects of organizational cynicism on incremental creativity cannot be effectively moderated when individuals intervene by facilitating personal trait regulatory focus. Also, the negative effects of organizational cynicism on radical creativity cannot be effectively moderated when individuals intervene by defensive personal trait regulatory focus. This paper finds out the boundary conditions of the path of organizational political climate loss by personal trait regulatory focus. Thus, this study hypothesizes that:

Hypothesis 4a. Facilitating personal trait regulatory focus moderates the relationships among organizational cynicism, self-interest behavior creativity and radical creativity. 
Hypothesis $\mathbf{4 b}$. Defensive personal trait regulatory focus moderates the relationships among organizational cynicism, self-interest behavior and incremental creativity.

Hypothesis 4c. Facilitating personal trait regulatory focus moderates the relationships among organizational cynicism, salary and promotion and radical creativity.

Hypothesis 4d. Defensive personal trait regulatory focus moderates the relationships among organizational cynicism, salary and promotion and incremental creativity.

Hypothesis 4e. Facilitating personal trait regulatory focus moderates the relationships among organizational cynicism, interpersonal relationship and radical creativity.

Hypothesis 4f. Defensive personal trait regulatory focus moderates the relationships among organizational cynicism, interpersonal relationship and incremental creativity.

Figure 1 shows the conceptual framework of the study which portrays the impact of organizational political climate, organizational cynicism, personal trait regulatory focus and dual innovation.

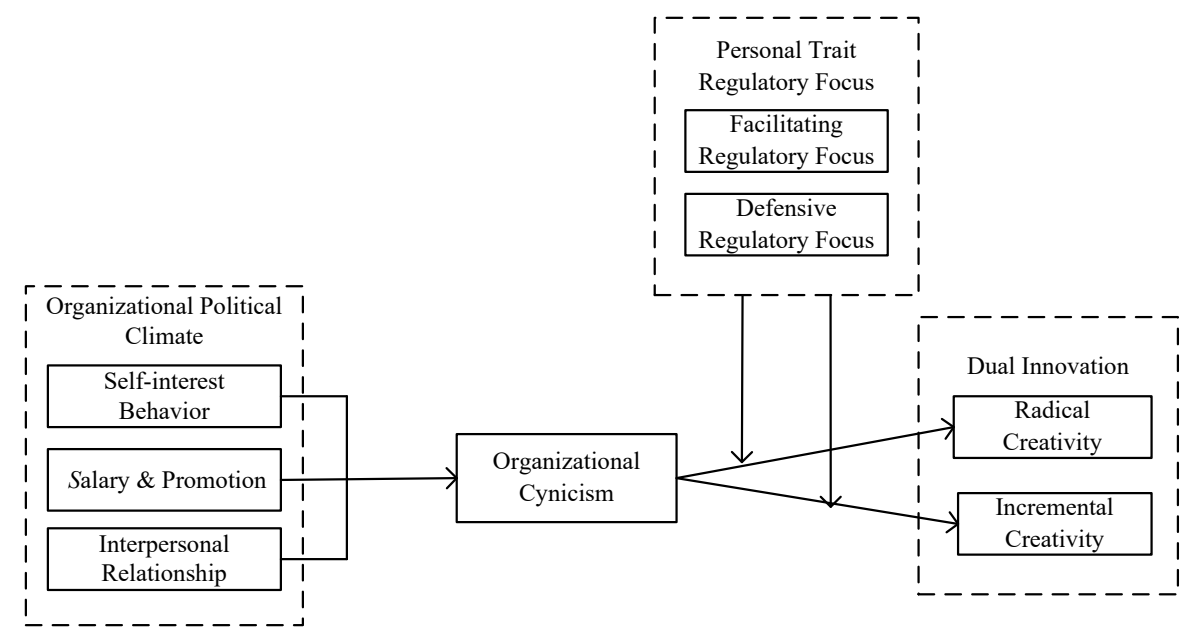

Figure 1. Conceptual framework.

\section{Materials and Methods}

\subsection{Study Design}

A quantitative research method with a survey questionnaire was adopted to explore the constructs related to this research in a well-known automobile enterprise " $\mathrm{H}$ " located in the Beijing-Tianjin-Hebei economic circle region in China. As a famous high-tech enterprise in the industry, independent research and independent innovation ability have been regarded as the key to the competitiveness of enterprise " $\mathrm{H}$ ". Enterprise " $\mathrm{H}$ " provided a rich number of samples for this study because it offered abundant job types, including research and development (R\&D) positions and design positions, and these positions required different types of innovations. Employees from R\&D and design positions could provide a sample source for measuring radical creativity. Employees from production positions provided a rich sample for this study to measure incremental creativity. Therefore, to some extent, the samples used in this study were representative.

\subsection{Measurement}

A survey questionnaire was applied in this research, covering demographic variables (age, gender, educational level, the tenure of work, position), organizational political climate, organizational cynicism, dual innovation and personal trait regulatory focus. 
The measurements adopted in this research were selected from past literature and translated from English into Chinese by professional translators. This study invited two bilingual professors of business to check the accuracy of the Chinese version to ensure translation validity. Additionally, a pilot test among 25 people was applied for the pre-test. The measurements for constructs were all seven-point Likert scales (from $1=$ strongly disagree to $7=$ strongly agree) and were verified to be reliable (Cronbach's alpha $>0.6)$.

The organizational political climate was measured by a 13-item scale from Kacmar et al. [50]. This measurement was divided into three dimensions, including self-serving behavior (4 items), compensation benefits and promotions ( 5 items) and the relationship between colleagues ( 4 items). The Cronbach's alpha of this measurement was 0.949 .

Dualistic innovation was measured by a 6-item scale from Madjar et al. [27]. This measurement was divided into two dimensions, including radical creativity (Cronbach's alpha of this dimension was 0.866) and incremental creativity (Cronbach's alpha of this dimension was 0.799).

Organizational cynicism was measured by a 13-item scale from Dean et al. [30]. This measurement was divided into three dimensions, including organizational cynicism belief, organizational cynicism emotion and organizational cynicism behavior. The Cronbach's alpha of this measurement was 0.834 .

Personal trait regulatory focus was measured by a 12-item scale from Wallace et al. [48]. This measurement was divided into two dimensions, including accelerative focus (6 items) and defensive focus (6 items). The Cronbach's alpha of this measurement was 0.90 .

Demographic variables were marked as control variables in this study to decline their influences on constructs [51]. To be specific, this study marked female as " 0 " and male as " 1 ". In addition, this study marked the position as a dummy variable (including operations, research and development, design, research and development support, research and development management, general staff and others) to define the difference between positions.

\subsection{Participants and Procedures}

This study used two methods to reduce common method bias. First, the supervisors were invited to assess the performance of their followers in creativity (radical creativity and incremental creativity). In the meantime, the employees were invited to respond to the survey about the political climate, the organizational cynicism and personal trait regulatory focus (facilitating regulatory focus and defensive regulatory focus). Secondly, this study collected data in three time periods. In the first period, 480 employees were invited to enroll the survey consisting of three parts: organizational political climate, organizational cynicism, and demographic variables. Three weeks later, the researchers sent questionnaires to the same group of employees to measure their personal trait regulatory focus. A month later, the researchers invited supervisors of the employees who filled the questionnaires at time periods 1 and 2 to rate the performance of employees in creativity. Finally, 341 effective samples were obtained after eliminating the incomplete response and the incomplete response, with a $91.6 \%$ effective response rate. To be specific, 89.2 percent were males and the rest were females. The average age of participants was 30.6 years old and the average length of work in the company was 3.8 years. Additionally, 68.1 percent of participants were bachelor's degree holders.

\section{Results}

\subsection{Descriptive Statistics and Correlations}

According to Table 1, descriptive statistics and correlation coefficients can be checked. There was a positive correlation between organizational political climate and organizational cynicism $(r=0.378$, $p<0.001)$. The organizational political climate is negatively correlated with radical creativity and incremental creativity $(\mathrm{r}=-0.130, p<0.05)$. Organizational cynicism was negatively correlated with radical $(\mathrm{r}=-0.243, p<0.001)$ and incremental creativity $(\mathrm{r}=-0.229, p<0.001)$. 
Table 1. Means, standard deviations, and correlations.

\begin{tabular}{|c|c|c|c|c|c|c|c|c|c|c|c|c|c|c|c|}
\hline Indicator & Means & S.D. & 1 & 2 & 3 & 4 & 5 & 6 & 7 & 8 & 9 & 10 & 11 & 12 & 13 \\
\hline Age & 30.78 & 7.80 & - & & & & & & & & & & & & \\
\hline Gender a & 0.89 & 0.31 & $-0.239 * *$ & - & & & & & & & & & & & \\
\hline Education & 3.36 & 0.93 & 0.043 & $-0.168 * *$ & - & & & & & & & & & & \\
\hline Tenure of work & 3.80 & 1.47 & $0.802 * * *$ & $-0.176^{* *}$ & -0.074 & - & & & & & & & & & \\
\hline Position $1^{\mathrm{c}}$ & 0.68 & 0.47 & $-0.217^{* * *}$ & $0.208^{* *}$ & -0.581 * & $-0.149 * *$ & - & & & & & & & & \\
\hline Position $2^{c}$ & 0.04 & 0.19 & -0.005 & -0.087 & $0.233 * *$ & -0.039 & $-0.281^{* *}$ & - & & & & & & & \\
\hline Position $3^{c}$ & 0.12 & 0.33 & 0.053 & $-0.161^{* *}$ & $0.340 * *$ & -0.024 & $-0.543^{* *}$ & -0.071 & - & & & & & & \\
\hline Position $4^{c}$ & 0.02 & 0.13 & -0.002 & -0.025 & $0.164^{* *}$ & -0.012 & $-0.197 * *$ & -0.026 & -0.049 & - & & & & & \\
\hline Position $5^{c}$ & 0.05 & 0.21 & 0.067 & -0.101 & $0.211^{* *}$ & 0.030 & $-0.326 * *$ & -0.042 & -0.082 & -0.030 & - & & & & \\
\hline Personal Trait Regulatory Focus & 5.38 & 0.98 & $0.135^{*}$ & $0.203^{* * *}$ & -0.078 & -0.080 & 0.086 & 0.011 & 0.018 & 0.056 & -0.090 & - & & & \\
\hline Organizational Political Climate & 5.55 & 0.78 & $-0.202 *$ & -0.027 & -0.023 & $-0.195^{* *}$ & -0.003 & -0.056 & -0.009 & 0.053 & -0.078 & -0.502 ** & & & \\
\hline Organizational Cynicism & 5.01 & 0.97 & -0.121 * & -0.150 ** & 0.093 & $-0.127^{*}$ & -0.064 & -0.030 & 0.000 & 0.005 & -0.033 & $-0.370^{* *}$ & $0.378^{* * *}$ & - & \\
\hline Radical Creativity & 5.06 & 0.99 & $-0.108 *$ & $0.242^{* * *}$ & $0.411 * *$ & -0.007 & $0.401 * * *$ & $-0.235 * *$ & $-0.210 * *$ & 0.007 & $-0.334^{* *}$ & $0.138 *$ & -0.130 * & $-0.243 * *$ & - \\
\hline Incremental Creativity & 5.31 & 0.86 & $-0.143^{* *}$ & $0.196^{* * *}$ & $0.308^{* *}$ & 0.061 & $0.318^{* * *}$ & $-0.119 *$ & -0.190 ** & 0.003 & $-0.225 * *$ & 0.125 * & $-0.131 *$ & $-0.229 * *$ & 0.188 \\
\hline
\end{tabular}




\subsection{Confirmatory Factor Analysis}

In this study, Mplus 6.0 was used for confirmatory factor analysis to examine the measurement model. Mplus is the mainstream analysis software for latent variable modeling. The software can deal with confirmatory factor analysis (CFA) and structural equation modelling (SEM) through simple programming techniques. It can be applied to measure different types of variables (e.g., continuous, censored, binary, ordered categorical, unordered categorical) by analyzing diversified data including cross-sectional data, longitudinal data, single-tier data and multi-tier data. In this study, the variables can be measured by cross-sectional and continuous data. Therefore, Mplus is an appropriate tool for analysis.

According to the suggestions, the values of $\chi^{2}$ goodness-of-fit test $\left(\chi^{2} / \mathrm{df}\right)$, the comparative fit index (CFI), Tucker-Lewis index (TLI), the root mean square error of approximation (RMSEA) and standardized root mean square residual (SRMR) could be adopted to explain the model fit [52,53]. The model fit indices reveal that to what extent the model reproduces the data.

$\chi^{2} / \mathrm{df}$ is used to measure the similarity between the observed covariance matrix and the expected variance matrix. It is believed that for an accepted model, the valued of $\chi^{2} / \mathrm{df}$ should be less than 5. CFI and TLI are used to compare the difference between the default model and the independent model. If the values of CFI and TLI are greater than 0.900 , and close to 1 , the model fit is satisfying. The RMSEA value is used to measure to what extent the model does not fit well. The value of this index should be less than 0.08 . The closer it is to 0 , the higher the goodness of fit. SRMR is the square root of the difference between the sample covariance matrix and the model covariance matrix. The value of SRMR should be less than 0.08 .

Table 2 showed that compared with the results of five-latent-factor model $(\mathrm{r}=157.955, p<0.01)$, four-latent-factor model $(\mathrm{r}=166.85, p<0.01)$, three-latent-factor model $(\mathrm{r}=483.271, p<0.01)$, two-latent-factor model $(\mathrm{r}=930.725, p<0.01)$, single-latent-factor model $(\mathrm{r}=1638.318, p<0.01)$. The results of the eight-latent-factor model indicates that $(499, \mathrm{~N}=341)=985.904, p=0.000$, RMSEA $=0.053$, CFI $=0.932, \mathrm{TLI}=0.923,=1.976$, suggesting that the measurement model was well established to realize discriminant validity. In addition, all the above abbreviations are shown in the Appendix A.

Table 2. Structural model fit and model comparison.

\begin{tabular}{ccccccc}
\hline Model & $\chi^{\mathbf{2}}$ & $\chi^{\mathbf{2} / \mathbf{d f}}$ & CFI & TLI & RMSEA & SRMR \\
\hline Quality Criteria & $>0$ & $<5$ & $>0.9$ & $>0.9$ & $<0.08$ & $<0.08$ \\
Eight-factor Model & 985.904 & 2.908 & 0.932 & 0.923 & 0.056 & 0.054 \\
Five-factor Model & 1060.790 & 2.955 & 0.899 & 0.886 & 0.071 & 0.071 \\
Four-factor Model & 1253.565 & 3.397 & 0.824 & 0.804 & 0.093 & 0.077 \\
Three-factor Model & 1887.520 & 5.047 & 0.785 & 0.785 & 0.102 & 0.091 \\
Two-factor Model & 2210.855 & 5.849 & 0.76 & 0.73 & 0.132 & 0.108 \\
One-factor Model & 2426.440 & 6.389 & 0.491 & 0.455 & 0.155 & 0.128 \\
\hline
\end{tabular}

\subsection{Results of Hypotheses Testing}

\subsubsection{Main Effects}

H1a-1c aimed to explore the influences of each dimension of organizational political climate on radical creativity and incremental creativity. The table below shows the results of regression and $\mathrm{H} 1 \mathrm{a}-1 \mathrm{~b}$ were supported; however, the $\mathrm{H} 1 \mathrm{c}$ was partially supported. To be specific, model 1 in the table showed that self-interest was negatively correlated with radical creativity and incremental creativity respectively $(\beta=-0.111, p=0.041 ; \beta=-0.098, p=0.046)$. Model 2 in the table showed that salary promotion was negatively correlated with radical creativity and incremental creativity respectively ( $\beta=-0.092, p=0.008 ; \beta=-0.106, p=0.005)$. Model 3 in the Table 3 showed that interpersonal relationships were not associated with incremental creativity $(\beta=-0.122, p=0.008)$, while, interpersonal relationships were negatively related to radical creativity ( $\beta=-0.153, p=0.055)$. 
Table 3. Regression analysis results.

\begin{tabular}{|c|c|c|c|c|c|c|c|c|c|c|}
\hline \multirow[b]{2}{*}{ Variable } & \multicolumn{2}{|c|}{ Model 1} & \multicolumn{2}{|c|}{ Model 2} & \multicolumn{2}{|c|}{ Model 3} & \multicolumn{2}{|c|}{ Model 4} & \multicolumn{2}{|c|}{ Model 5} \\
\hline & $\begin{array}{c}\text { Radical } \\
\text { Creativity }\end{array}$ & $\begin{array}{l}\text { Incremental } \\
\text { Creativity }\end{array}$ & $\begin{array}{c}\text { Radical } \\
\text { Creativity }\end{array}$ & $\begin{array}{l}\text { Incremental } \\
\text { Creativity }\end{array}$ & $\begin{array}{c}\text { Radical } \\
\text { Creativity }\end{array}$ & $\begin{array}{l}\text { Incremental } \\
\text { Creativity }\end{array}$ & $\begin{array}{c}\text { Radical } \\
\text { Creativity }\end{array}$ & $\begin{array}{c}\text { Incremental } \\
\text { Creativity }\end{array}$ & $\begin{array}{c}\text { Radical } \\
\text { Creativity }\end{array}$ & $\begin{array}{l}\text { Incremental } \\
\text { Creativity }\end{array}$ \\
\hline Gender $^{a}$ & $0.408 * *$ & 0.274 & 0.416 & 0.284 & $0.423 *$ & 0.287 & 0.403 & 0.271 & 0.293 & 0.182 \\
\hline Age & -0.017 & -0.013 & -0.017 & -0.013 & -0.015 & -0.012 & -0.014 & -0.012 & -0.017 & -0.013 \\
\hline Education & $-0.237^{* *}$ & $-0.160 *$ & $-0.241^{* * *}$ & $-0.165^{* *}$ & $-0.230^{* * *}$ & $-0.154 * *$ & $-0.224 * * *$ & $-0.152 * *$ & $-0.217^{* * *}$ & -0.143 * \\
\hline Tenure of work & 0.096 & 0.041 & 0.093 & 0.039 & 0.098 & 0.042 & 0.098 & 0.040 & 0.097 & 0.042 \\
\hline Position $1^{\mathrm{b}}$ & 0.141 & 0.174 & 0.133 & 0.173 & 0.152 & 0.179 & 0.113 & 0.146 & 0.099 & 0.137 \\
\hline Position $2 \mathrm{~b}$ & $-0.928 * * *$ & -0.265 & $-0.935^{* * *}$ & -0.272 & $-0.918^{* * *}$ & -0.257 & $-0.940 * * *$ & -0.273 & $-0.938^{* * *}$ & -0.274 \\
\hline Position $3^{b}$ & -0.302 & -0.184 & -0.312 & -0.185 & -0.301 & -0.186 & -0.352 & -0.224 & $-0.400 *$ & -0.265 \\
\hline Position $4^{\mathrm{b}}$ & 0.375 & 0.328 & 0.326 & 0.293 & 0.366 & 0.313 & 0.409 & 0.321 & 0.291 & 0.249 \\
\hline Position $5^{b}$ & $-1.210^{* * *}$ & -0.584 & $-1.210^{* * *}$ & -0.569 & $-1.194^{* * *}$ & -0.576 & $-1.228^{* * *}$ & $-0.613 *$ & $-1.355^{* * *}$ & $-0.700^{* *}$ \\
\hline Self-interest Behavior & -0.111 * & -0.098 * & & & & & & & & \\
\hline Salary \& Promotion & & & $-0.092 * *$ & -0.106 ** & & & & & & \\
\hline Interpersonal Relationship & & & & & -0.153 & $-0.122 * *$ & & & & \\
\hline Organizational Cynicism & & & & & & & $-0.177^{* * *}$ & $-0.101 *$ & & \\
\hline Personal Trait Regulatory Focus & & & & & & & & & 0.000 & 0.001 \\
\hline $\begin{array}{l}\text { Organizational Cynicism * } \\
\text { Facilitating Regulatory Focus }\end{array}$ & & & & & & & & & $0.284^{* *}$ & 0.371 \\
\hline Organizational Cynicism * & & & & & & & & & 0.145 & $0.206^{* *}$ \\
\hline $\begin{array}{l}\text { Derensive Regulatory rocus } \\
\text { F }\end{array}$ & 15.378 & 7.104 & 15.207 & 7.198 & 15.800 & 7.272 & 16.508 & 7.178 & 15.757 & 7.525 \\
\hline $\mathrm{R}^{2}$ & 0.318 & 0.177 & 0.315 & 0.179 & 0.324 & 0.181 & 0.333 & 0.179 & 0.366 & 0.216 \\
\hline
\end{tabular}

Note: ${ }^{*} p<0.05 ;{ }^{* *} p<0.01 ; * * * p<0.001$. Gender ${ }^{\mathrm{a}}$ : Female $=1$, Male $=0$. Position ${ }^{\mathrm{b}}: 1=\mathrm{R} \& \mathrm{D}$ Position, $2=$ Design Position; $3=$ Design Position; $4=\mathrm{R} \& \mathrm{D}$ Support Position; $5=\mathrm{R} \& \mathrm{D}$ Management Position. 


\subsubsection{Mediating Effects}

The PROCESS program proposed was used by applying a bootstrap 5000 times to test the mediating effect (H2a-2d) [54]. The table showed that $\mathrm{H} 2 \mathrm{a}-2 \mathrm{~d}$ were all supported. H2a predicted that organizational cynicism positively mediated the effect of intellectual stimulation on radical creativity. The results showed that the $95 \%$ confidence interval for direct effect was [ $-0.0658,0.1540]$, containing 0 ; while the $95 \%$ confidence interval for indirect effect was [0.0307, 0.1147], excluding 0 . Therefore, organizational cynicism mediated self-serving behavior and radical creativity. $\mathrm{H} 2 \mathrm{~b}$ predicted that the organizational cynicism positively mediated the effect of encouraging incentive on incremental creativity. The results showed that the 95\% confidence interval for direct effect was [ $-0.0491,0.1565]$, containing 0 , while the $95 \%$ confidence interval for indirect effect was [0.0179, 0.0979], excluding 0 . Therefore, organizational cynicism positively mediated the effect of encouraging incentives for incremental creativity. $\mathrm{H} 2 \mathrm{c}$ predicted that organizational cynicism mediated the positive correlation between the idealized influence and radical creativity. The results showed that the confidence interval of $95 \%$ of the direct effect was [-0.0421, 0.1948], including 0 , while the confidence interval of $95 \%$ of the indirect effect was $[0.0337,0.1326]$, excluding 0 . Therefore, organizational cynicism positively mediated the effect of salary promotion on radical creativity. In the meantime, H2c also predicted that the organizational cynicism mediated the positive correlation between the idealized influence and incremental creativity. The results showed that the confidence interval of $95 \%$ of the direct effect was $[-0.0545,0.1716]$, containing 0 , while, the confidence interval of $95 \%$ of the indirect effect was $[0.0224,0.1159]$, excluding 0 . Therefore, organizational cynicism positively mediated the effect of salary promotion on incremental creativity. $\mathrm{H} 2 \mathrm{~d}$ predicted that organizational cynicism mediated the positive correlation between the interpersonal relationship and radical creativity. The results showed that the $95 \%$ confidence interval for direct effect was [0.0058, 0.2189], excluding 0 , while the $95 \%$ confidence interval for indirect effect was $[0.0239,0.1172]$, excluding 0 . Therefore, organizational cynicism positively mediated the effect of interpersonal relationship on radical creativity. $\mathrm{H} 2 \mathrm{~d}$ also predicted that organizational cynicism mediated the positive correlation between the interpersonal relationship and incremental creativity. Table 4 showed that the confidence interval of direct effect $95 \%$ was $[-0.0614,0.1429]$, containing 0 , while the confidence interval of indirect effect $95 \%$ was [0.0211, $0.1101]$, excluding 0 . Therefore, organizational cynicism positively mediated the effect of interpersonal relationship on incremental creativity.

Table 4. Mediation effect test results.

\begin{tabular}{|c|c|c|c|c|}
\hline Relationship & Direct & 95\% Conf. & Indirect & 95\% Conf. \\
\hline $\begin{array}{l}\text { Self-interested Behavior } \rightarrow \text { Organizational } \\
\text { Cynicism } \rightarrow \text { Radical Creativity }\end{array}$ & 0.0441 & {$[-0.0658,0.1540]$} & 0.0668 & {$[0.0307,0.1147]$} \\
\hline $\begin{array}{l}\text { Self-interested Behavior } \rightarrow \text { Organizational } \\
\text { Cynicism } \rightarrow \text { Incremental Creativity }\end{array}$ & 0.0537 & {$[-0.0491,0.1565]$} & 0.0525 & {$[0.0179,0.0979]$} \\
\hline $\begin{array}{l}\text { Salary and Promotion } \rightarrow \text { Organizational } \\
\quad \text { Cynicism } \rightarrow \text { Radical Creativity }\end{array}$ & 0.0763 & {$[-0.0421,0.1948]$} & 0.0763 & {$[0.0337,0.1326]$} \\
\hline $\begin{array}{l}\text { Salary and Promotion } \rightarrow \text { Organizational } \\
\text { Cynicism } \rightarrow \text { Incremental creativity }\end{array}$ & 0.0586 & {$[-0.0545,0.1716]$} & 0.0639 & {$[0.0224,0.1159]$} \\
\hline $\begin{array}{l}\text { Interpersonal Relationships } \rightarrow \text { Organizational } \\
\quad \text { Cynicism } \rightarrow \text { Radical Creativity }\end{array}$ & 0.1124 & {$[0.0058,0.2189]$} & 0.0644 & {$[0.0239,0.1172]$} \\
\hline $\begin{array}{l}\text { Interpersonal Relationships } \rightarrow \text { Organizational } \\
\quad \text { Cynicism } \rightarrow \text { Incremental Creativity }\end{array}$ & 0.0407 & {$[-0.0614,0.1429]$} & 0.0606 & {$[0.0211,0.1101]$} \\
\hline
\end{tabular}

\subsubsection{Moderating Effect}

To better test H3a-3b, two actions were conducted according to the suggestions [55]. First, the cynicism, accelerative focus, and restrictive focus were centralized to calculate the interaction terms. Second, the cynicism, accelerative focus, restrictive focus, the interaction terms and control variables were enrolled in the regression stage. Table 3 showed that the accelerative focus positively moderated the effect of cynicism on radical creativity $(\beta=0.284, p=0.001)$. Therefore, H3a was supported. 
Additionally, Table 3 showed that the restrictive focus significantly moderated the effect of cynicism on incremental creativity $(\beta=0.206, p=0.004)$. Therefore, H3b was supported. However, the accelerative focus did not significantly moderate the effect of cynicism on radical creativity ( $\beta=0.371, p=0.057$ ), and the restrictive focus did not significantly moderate the effect of cynicism on incremental creativity ( $\beta=0.145, p=0.054)$. Figure 2 presented the moderating effects of defensive regulatory focus $(\mathbf{a}, \mathbf{b})$ and facilitating regulatory focus $(\mathbf{c}, \mathbf{d})$.

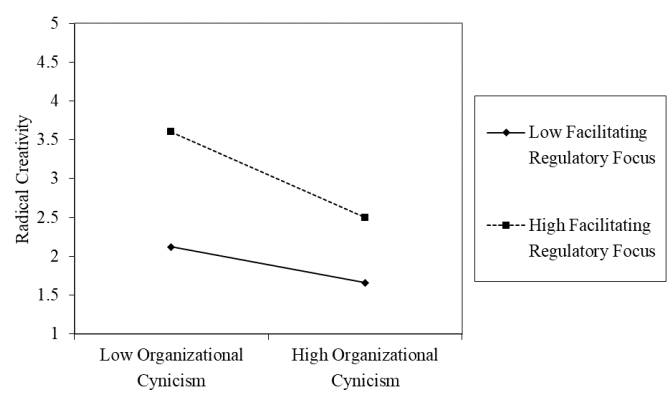

(a)

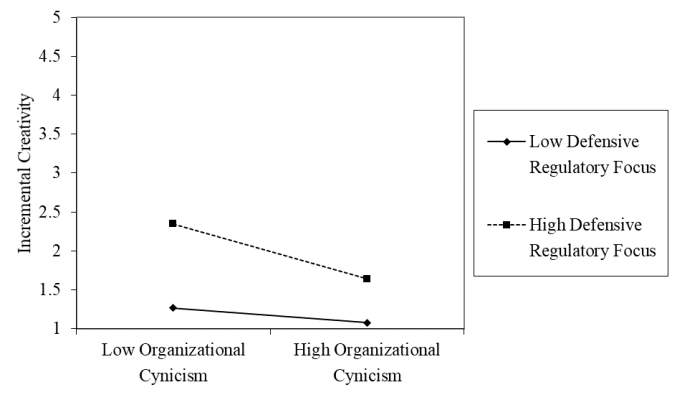

(c)

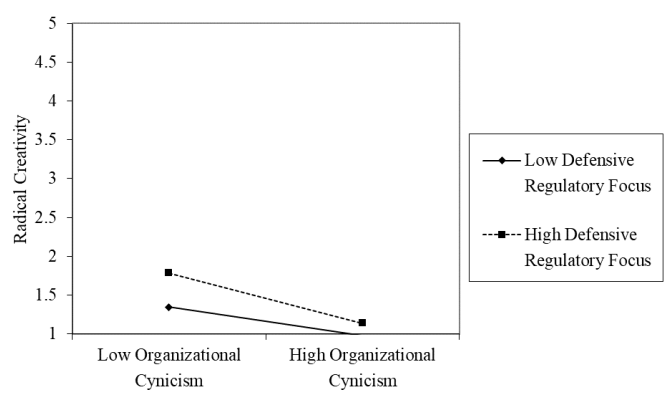

(b)

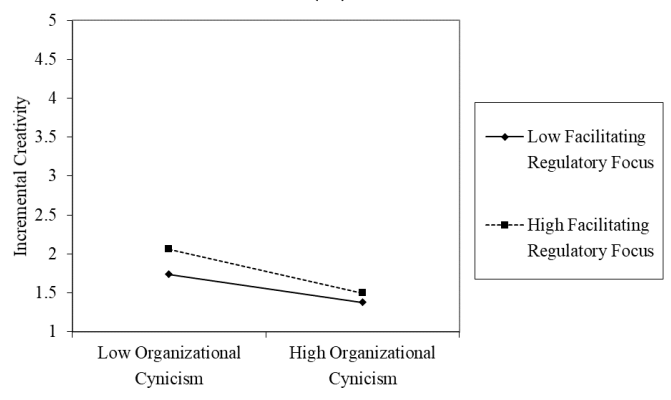

(d)

Figure 2. Graphic presentations of the moderating effects of defensive regulatory focus (a,b) and facilitating regulatory focus $(\mathbf{c}, \mathbf{d})$.

\subsubsection{Mediating Effect with Moderators on the Main Path}

H4a predicted that the accelerative focus moderated the mediating effect of organizational cynicism on the effect of self-serving behavior on radical creativity. The results showed that the $95 \%$ confidence interval was [0.0225, 0.0977], excluding 0 . Therefore, the H4a was supported. H4b predicted that the restrictive focus moderated the mediating effect of organizational cynicism on the effect of self-serving behavior on incremental creativity. The results showed that the $95 \%$ confidence interval range is $[0.0114,0.0783]$, excluding 0 . Therefore, $\mathrm{H} 4 \mathrm{~b}$ was supported. $\mathrm{H} 4 \mathrm{c}$ predicted that the accelerative focus moderated the mediating effect of organizational cynicism on the effect of salary promotion on radical creativity. The results showed that the $95 \%$ confidence interval range was [0.0277, 0.1127], excluding 0 . Therefore, the $\mathrm{H} 4 \mathrm{c}$ was supported. $\mathrm{H} 4 \mathrm{~d}$ predicted that the accelerative focus moderated the mediating effect of organizational cynicism on the effect of salary promotion on incremental creativity. The results showed that the $95 \%$ confidence interval range was [0.0138, 0.0932], excluding 0 . Therefore, H4d was supported. H4e predicted that the accelerative focus moderated the mediating effect of organizational cynicism on the effect of interpersonal relationships on radical creativity. The results showed that the $95 \%$ confidence interval range was $[0.0249,0.1038]$, excluding 0 . Therefore, the $\mathrm{H} 4 \mathrm{e}$ was supported. $\mathrm{H} 4 \mathrm{f}$ predicted that the restrictive focus moderated the mediating effect of organizational cynicism on the effect of interpersonal relationship on incremental creativity. The results showed that the $95 \%$ confidence interval range was [0.0118, 0.0867], excluding 0 . Therefore, the H4f was supported. 


\section{Discussion}

\subsection{Findings}

This study explores the influence of organizational political climate on employees' dual creativity based on self-determination theory and the role of organizational cynicism. The findings can be summarized as follows:

\subsubsection{The Negative Effect of Organizational Political Climate and the Mediating Effect of Organizational Cynicism}

The research finds that the dimensions of organizational political climate about self-interested behavior and salary and promotion are negative to employees' performance in innovation. Additionally, organizational cynicism is considered to mediate the effect of self-interested behavior on creativity and mediates the effect of salary and promotion on creativity. As employees are immersed in a high degree organizational political climate, they will be sensitive to issues about self-interested behavior and salary and promotion, and they may less devote themselves into work and innovation and creation as they feel unjust about their treatment.

However, interpersonal relationships are only negatively related to incremental creativity and not obviously related to radical creativity. This reveals that the high-degree political climate may influence the innovative behaviours more in reformations of the present situation than in comprehensive innovation. Furthermore, organizational cynicism is considered to mediate the effect of interpersonal relationships on incremental creativity. This shows that employees' passion for reformation is influenced by their perceptions about relationships among colleagues. If they perceive that the relationships among colleagues are distant, they may less care about others' opinions and conduct less reformative actions in their work places.

\subsubsection{Moderating Effect of Personal Trait Regulatory Focus}

The findings show that as people have a facilitating personal trait regulatory focus, the negative effect of cynicism on radical creativity can decline. However, as people have a defensive personal trait regulatory focus, the negative effect of cynicism on incremental creativity can decline. Additionally, facilitating personal trait regulatory focus can moderate the mediating effect of cynicism on the relationship between organizational political climate and radical creativity, while defensive personal trait regulatory focus can moderate the mediating effect of cynicism on the relationship between organizational political climate and incremental creativity.

\section{Conclusions}

The research shows that the negative effects of organizational political climate and organizational cynicism on employees' performance are not irreversible. This study regards cynicism as a dynamic variable and the personal trait regulatory focuses as a moderating variable in the organizational political climate. The results show that: first, self-interested behavior and salary and promotion are negatively related to creativity. However, interpersonal relationships are only negatively related to incremental creativity and not obviously related to radical creativity. Second, organizational cynicism mediates the effect of self-interested behavior on creativity and mediates the effect of salary and promotion on creativity. However, organizational cynicism only mediates the effect of interpersonal relationships on incremental creativity. Third, as people have the facilitating personal trait regulatory focus, the negative effect of cynicism on radical creativity can decline. As people have the defensive personal trait regulatory focus, the negative effect of cynicism on incremental creativity can decline. Fourth, a facilitating personal trait regulatory focus can moderate the mediating effect of cynicism on the relationship between organizational political climate and radical creativity, while a defensive personal trait regulatory focus can moderate the mediating effect of cynicism on the relationship 
between organizational political climate and incremental creativity. This study not only fills the gap in the literature, but also can be referred to by practitioners for management.

\subsection{Implications}

The theoretical contributions of this study are as follows. First, this study provides a new research perspective for understanding "how to restrain the negative effects of organizational political climate" and expands the research scope of the relationship between "organizational climate-creativity" [56,57]. Secondly, this study enriches the research on antecedents and their influencing mechanisms of the two types of creativity. At present, most studies on creativity focus on the exploration of antecedents [58], however, few studies discuss a certain antecedent and its mediating mechanism. This study enriches the research in creativity by exploring how the mechanism of organizational cynicism mediates the relationship between organizational political climate and creativity from the perspective of the organizational environment. Third, this study expands the research of personal trait regulatory focus. Past literature mostly discusses the effect of personal trait regulatory focus on satisfaction [59], performance [60] and motivation [49], while few studies discuss the effect of focus on creativity. This study verifies the moderating effect of personal trait regulatory focus, a kind of personal trait, on the relationship between organizational cynicism and creativity, enriching the relevant research and providing a possible perspective for future studies on the theoretical boundary of creativity.

This study also can be referred to for practice. First, organizations may help employees to inspire innovation. As employees work in a position that they are adept in, they may be more willing to contribute to organizations [61]. If the employees recognize their role in contributing to innovation and transformation, they may be more proactive and innovative. In addition, organizations may conduct different policies to inspire their innovation and motivation according to the types of employees. For the talented employees and knowledge employees, facilitating policies may be carried out to encourage radical innovation. Compared with general workers, talented employees and knowledge employees usually acquire skills faster and apply knowledge more flexibly, and therefore, the positive climate and policy may inspire their talents to contribute to innovation and creation for the transformation of organizations. For general workers, perceptions about interpersonal relationships should consider which influences incremental creativity. Since general workers used to be the people who know the emerging problems of work, their attitudes determine the performance of organizations. Thus, organizations should be concerned with the feelings of those workers and assist these employees in setting work goals and balancing their work and life well according to their personal characteristics. Furthermore, organizations may encourage general workers to reform ways of working to overcome problems in daily work.

Second, organizations may develop systematic staff training courses about personal trait regulatory focus to cultivate the values of employees and build positive climates for employees. Third, organizations may optimize staff deployment and recruitment by arranging for employees to have a facilitating personal trait regulatory focus to different departments to decrease the negative effect of the organizational political climate. In addition, organizations may deploy people with defensive focuses to risk-control departments, while assigning people with facilitating focus to more innovative and open positions.

\subsection{Limitation and Future Research}

As with all studies, this study has some limitations. First, this study only explores the perceptions of employees from one automobile industry in China. The limitation in sample size and cultural and industrial diversity of the case cannot be omitted. Future research can test the model with broad contexts and a larger sample size. Second, this study applies quantitative research (survey-based) for collecting data, however, a single research method cannot reflect the whole phenomenon. Therefore, future research may apply a mixed method to explore similar phenomena. Moreover, this study was not concerned with contextual factors and individual factors completely, and individual factors, 
contextual factors and their interactions may influence creativity [62]. Therefore, future research may explore the interactive effect of individual factors and contextual factors, motivation, psychological empowerment and committees in the study of creativity.

Author Contributions: Conceptualization, Q.Z. and X.Z.; methodology, Q.Z. and S.S.; resources, X.Z.; writing — original draft preparation, Q.Z. \& S.S.; writing—review and editing, X.Z. \& W.L.; funding acquisition, W.L.

Funding: This research is supported by the National Social Science Foundation of China (Grant No. 17CGJ002).

Acknowledgments: We would like to thank the governments and institutes who offered funds for this research, and the students and colleagues who gave support for the data collection. Furthermore, we also would like to thank the anonymous reviewers and editors for commenting on this paper.

Conflicts of Interest: The authors declare no conflict of interest.

\section{Appendix A}

Table A1. Abbreviations.

\begin{tabular}{cc}
\hline Full Name of Terms & Abbreviations \\
\hline Research and development & R\&D \\
Standard deviation & S.D. \\
Confirmatory factor analysis & CFA \\
Structural equation modelling & SEM \\
$\chi^{2}$ goodness-of-fit test & $\chi^{2} / \mathrm{df}$ \\
The comparative fit index & CFI \\
Tucker-Lewis index & TLI \\
The root mean square error of approximation & RMSEA \\
Standardized root mean square residual & SRMR \\
\hline
\end{tabular}

\section{References}

1. Ehnert, I.; Parsa, S.; Roper, I.; Wagner, M.; Muller-Camen, M. Reporting on sustainability and HRM: A comparative study of sustainability reporting practices by the world's largest companies. Int. J. Hum. Resour. Manag. 2016, 27, 88-108. [CrossRef]

2. Ozolina-Ozola, I. The impact of human resource management practices on employee turnover. Procedia-Soc. Behav. Sci. 2014, 156, 223-226. [CrossRef]

3. Taylor, S.; Beechler, S.; Napier, N. Toward an integrative model of strategic international human resource management. Acad. Manag. Rev. 1996, 21, 959-985. [CrossRef]

4. Presley, A.; Meade, L.; Sarkis, J. A strategic sustainability justification methodology for organizational decisions: A reverse logistics illustration. Int. J. Prod. Res. 2007, 45, 4595-4620. [CrossRef]

5. Becker, B.; Gerhart, B. The impact of human resource management on organizational performance: Progress and prospects. Acad. Manag. J. 1996, 39, 779-801.

6. Dao, V.; Langella, I.; Carbo, J. From green to sustainability: Information Technology and an integrated sustainability framework. J. Strateg. Inf. Syst. 2011, 20, 63-79. [CrossRef]

7. Boudreau, J.W.; Ramstad, P.M. Talentship, talent segmentation, and sustainability: A new HR decision science paradigm for a new strategy definition. Hum. Resour. Manag. Publ. Cooperation Sch. Bus. Adm. Univ. Mich. Alliance Soc. Hum. Resour. Manag. 2005, 44, 129-136. [CrossRef]

8. Lee, M.D.P. A review of the theories of corporate social responsibility: Its evolutionary path and the road ahead. Int. J. Manag. Rev. 2008, 10, 53-73. [CrossRef]

9. Kramar, R. Beyond strategic human resource management: Is sustainable human resource management the next approach? Int. J. Hum. Resour. Manag. 2014, 25, 1069-1089. [CrossRef]

10. Järlström, M.; Saru, E.; Vanhala, S. Sustainable human resource management with salience of stakeholders: A top management perspective. J. Bus. Ethics 2018, 152, 703-724. [CrossRef]

11. Hobelsberger, C. Sustainability and HRM in international supply chains. In Sustainability and Human Resource Management; Springer: Berlin/Heidelberg, Germany, 2014; pp. 379-400. 
12. Ehnert, I. Sustainable human resource management. In A Conceptual and Exploratory Analysis from a Paradox Perspective; Springer: Heidelberg, Germany, 2009.

13. Baum, T. Sustainable human resource management as a driver in tourism policy and planning: A serious sin of omission? J. Sustain. Tour. 2018, 26, 873-889. [CrossRef]

14. Lewis, R.E.; Heckman, R.J. Talent management: A critical review. Hum. Resour. Manag. Rev. 2006, 16, $139-154$. [CrossRef]

15. Gollan, P.J. High involvement management and human resource sustainability: The challenges and opportunities. Asia Pac. J. Hum. Resour. 2005, 43, 18-33. [CrossRef]

16. Lawson, B.; Samson, D. Developing innovation capability in organisations: A dynamic capabilities approach. Int. J. Innov. Manag. 2001, 5, 377-400. [CrossRef]

17. Chang, C.-H.; Rosen, C.C.; Levy, P.E. The relationship between perceptions of organizational politics and employee attitudes, strain, and behavior: A meta-analytic examination. Acad. Manag. J. 2009, 52, 779-801. [CrossRef]

18. Chiaburu, D.S.; Peng, A.C.; Oh, I.-S.; Banks, G.C.; Lomeli, L.C. Antecedents and consequences of employee organizational cynicism: A meta-analysis. J. Vocat. Behav. 2013, 83, 181-197. [CrossRef]

19. Landells, E.; Albrecht, S.L. Organizational political climate: Shared perceptions about the building and use of power bases. Hum. Resour. Manag. Rev. 2013, 23, 357-365. [CrossRef]

20. Drory, A.; Romm, T. The definition of organizational politics: A review. Hum. Relat. 1990, 43, $1133-1154$. [CrossRef]

21. Rosen, C.C.; Harris, K.J.; Kacmar, K.M. The emotional implications of organizational politics: A process model. Hum. Relat. 2009, 62, 27-57. [CrossRef]

22. Kacmar, K.M.; Bachrach, D.G.; Harris, K.J.; Zivnuska, S. Fostering good citizenship through ethical leadership: Exploring the moderating role of gender and organizational politics. J. Appl. Psychol. 2011, 96, 633. [CrossRef]

23. Yu, C.; Yu, T.-F.; Yu, C.-C. Knowledge sharing, organizational climate, and innovative behavior: A cross-level analysis of effects. Soc. Behav. Pers. Int. J. 2013, 41, 143-156. [CrossRef]

24. Landells, E.M.; Albrecht, S.L. The positives and negatives of organizational politics: A qualitative study. J. Bus. Psychol. 2017, 32, 41-58. [CrossRef]

25. Sternberg, R.J. A propulsion model of types of creative contributions. Rev. Gen. Psychol. 1999, 3, 83. [CrossRef]

26. Kaufman, J.C.; Beghetto, R.A. Beyond big and little: The four c model of creativity. Rev. Gen. Psychol. 2009, 13, 1. [CrossRef]

27. Madjar, N.; Greenberg, E.; Chen, Z. Factors for radical creativity, incremental creativity, and routine, noncreative performance. J. Appl. Psychol. 2011, 96, 730. [CrossRef]

28. Unsworth, K. Unpacking creativity. Acad. Manag. Rev. 2001, 26, 289-297. [CrossRef]

29. Gilson, L.L.; Madjar, N. Radical and incremental creativity: Antecedents and processes. Psychol. Aesthetics Creativity Arts 2011, 5, 21. [CrossRef]

30. Dean, J.W., Jr.; Brandes, P.; Dharwadkar, R. Organizational cynicism. Acad. Manag. Rev. 1998, 23, $341-352$. [CrossRef]

31. Johnson, J.L.; O'Leary-Kelly, A.M. The effects of psychological contract breach and organizational cynicism: Not all social exchange violations are created equal. J. Organ. Behav. Int. J. Ind. Occup. Organ. Psychol. Behav. 2003, 24, 627-647. [CrossRef]

32. Neves, P. Organizational cynicism: Spillover effects on supervisor-subordinate relationships and performance. Leadersh. Q. 2012, 23, 965-976. [CrossRef]

33. Andersson, L.M.; Bateman, T.S. Cynicism in the workplace: Some causes and effects. J. Organ. Behav. Int. J. Ind. Occup. Organ. Psychol. Behav. 1997, 18, 449-469. [CrossRef]

34. Harrell-Cook, G.; Ferris, G.R.; Dulebohn, J.H. Political behaviors as moderators of the perceptions of organizational politics-Work outcomes relationships. J. Organ. Behav. 1999, 20, 1093-1105. [CrossRef]

35. Wilkerson, J.M.; Evans, W.R.; Davis, W.D. A test of coworkers' influence on organizational cynicism, badmouthing, and organizational citizenship behavior. J. Appl. Soc. Psychol. 2008, 38, 2273-2292. [CrossRef]

36. Brandes, P.; Castro, S.L.; James, M.S.; Martinez, A.D.; Matherly, T.A.; Ferris, G.R.; Hochwarter, W.A. The interactive effects of job insecurity and organizational cynicism on work effort following a layoff. J. Leadersh. Organ. Stud. 2008, 14, 233-247. [CrossRef] 
37. Treadway, D.C.; Hochwarter, W.A.; Ferris, G.R.; Kacmar, C.J.; Douglas, C.; Ammeter, A.P.; Buckley, M.R. Leader political skill and employee reactions. Leadersh. Q. 2004, 15, 493-513. [CrossRef]

38. Koseoglu, G.; Liu, Y.; Shalley, C.E. Working with creative leaders: Exploring the relationship between supervisors' and subordinates' creativity. Leadersh. Q. 2017, 28, 798-811. [CrossRef]

39. Hochwarter, W.A.; James, M.; Johnson, D.; Ferris, G.R. The Interactive Effects of Politics Perceptions and Trait Cynicism on Work Outcomes. J. Leadersh. Organ. Stud. 2004, 10, 44-57. [CrossRef]

40. Gkorezis, P.; Petridou, E.; Xanthiakos, P. Leader positive humor and organizational cynicism: LMX as a mediator. Leadersh. Organ. Dev. J. 2014, 35, 305-315. [CrossRef]

41. Nazir, T.; Ahmad, U.N.B.U.; Nawab, S.; Shah, S.F.H. Mediating role of organizational cynicism in relationship between role stressors and turnover intention: Evidence from healthcare sector of Pakistan. Int. Rev. Manag. Mark. 2016, 6, 199-204.

42. Jiang, H.; Chen, Y.; Sun, P.; Li, C. Authoritarian leadership and employees' unsafe behaviors: The mediating roles of organizational cynicism and work alienation. Curr. Psychol. 2017, 1-11. [CrossRef]

43. Higgins, E.T. Beyond pleasure and pain. Am. Psychol. 1997, 52, 1280. [CrossRef] [PubMed]

44. Idson, L.C.; Liberman, N.; Higgins, E.T. Distinguishing gains from nonlosses and losses from nongains: A regulatory focus perspective on hedonic intensity. J. Exp. Soc. Psychol. 2000, 36, 252-274. [CrossRef]

45. Tumasjan, A.; Braun, R. In the eye of the beholder: How regulatory focus and self-efficacy interact in influencing opportunity recognition. J. Bus. Ventur. 2012, 27, 622-636. [CrossRef]

46. Tuncdogan, A.; Van Den Bosch, F.; Volberda, H. Regulatory focus as a psychological micro-foundation of leaders' exploration and exploitation activities. Leadersh. Q. 2015, 26, 838-850. [CrossRef]

47. Manczak, E.M.; Zapata-Gietl, C.; McAdams, D.P. Regulatory focus in the life story: Prevention and promotion as expressed in three layers of personality. J. Pers. Soc. Psychol. 2014, 106, 169. [CrossRef] [PubMed]

48. Wallace, J.C.; Johnson, P.D.; Frazier, M.L. An examination of the factorial, construct, and predictive validity and utility of the regulatory focus at work scale. J. Organ. Behav. Int. J. Ind. Occup. Organ. Psychol. Behav. 2009, 30, 805-831. [CrossRef]

49. Peng, A.C.; Dunn, J.; Conlon, D.E. When vigilance prevails: The effect of regulatory focus and accountability on integrative negotiation outcomes. Organ. Behav. Hum. Decis. Processes 2015, 126, 77-87. [CrossRef]

50. Kacmar, K.M.; Carlson, D.S. Further validation of the perceptions of politics scale (POPS): A multiple sample investigation. J. Manag. 1997, 23, 627-658. [CrossRef]

51. Ng, T.W.; Feldman, D.C. The relationship of age to ten dimensions of job performance. J. Appl. Psychol. 2008, 93, 392. [CrossRef] [PubMed]

52. Medsker, G.J.; Williams, L.J.; Holahan, P.J. A review of current practices for evaluating causal models in organizational behavior and human resources management research. J. Manag. 1994, 20, 439-464. [CrossRef]

53. Wang, M.; Russell, S.S. Measurement equivalence of the job descriptive index across Chinese and American workers: Results from confirmatory factor analysis and item response theory. Educ. Psychol. Meas. 2005, 65, 709-732. [CrossRef]

54. Bolin, J.H. Hayes, Andrew F. (2013). Introduction to Mediation, Moderation, and Conditional Process Analysis: A Regression-Based Approach. New York, NY: The Guilford Press. J. Educ. Meas. 2014, 51, 335-337. [CrossRef]

55. Dawson, J.F.; Richter, A.W. Probing three-way interactions in moderated multiple regression: Development and application of a slope difference test. J. Appl. Psychol. 2006, 91, 917. [CrossRef] [PubMed]

56. Kaya, N.; Aydin, S.; Ongun, G. The impacts of servant leadership and organizational politics on burnout: A research among mid-level managers. Int. J. Bus. Adm. 2016, 7, 26. [CrossRef]

57. Lau, P.Y.Y.; Tong, J.L.T.; Lien, B.Y.-H.; Hsu, Y.-C.; Chong, C.L. Ethical work climate, employee commitment and proactive customer service performance: Test of the mediating effects of organizational politics. J. Retail. Consum. Serv. 2017, 35, 20-26. [CrossRef]

58. Wallace, J.C.; Butts, M.M.; Johnson, P.D.; Stevens, F.G.; Smith, M.B. A multilevel model of employee innovation: Understanding the effects of regulatory focus, thriving, and employee involvement climate. J. Manag. 2016, 42, 982-1004. [CrossRef]

59. Zhao, X.R.; Namasivayam, K. The relationship of chronic regulatory focus to work-family conflict and job satisfaction. Int. J. Hosp. Manag. 2012, 31, 458-467. [CrossRef]

60. Zhang, S.; Cornwell, J.F.; Higgins, E.T. Repeating the past: Prevention focus motivates repetition, even for unethical decisions. Psychol. Sci. 2014, 25, 179-187. [CrossRef] 
61. Benner, M.J.; Tushman, M.L. Exploitation, exploration, and process management: The productivity dilemma revisited. Acad. Manag. Rev. 2003, 28, 238-256. [CrossRef]

62. Woodman, R.W.; Sawyer, J.E.; Griffin, R.W. Toward a theory of organizational creativity. Acad. Manag. Rev. 1993, 18, 293-321. [CrossRef] 